\title{
Conditional expression of oncogenic $K$-ras from its endogenous promoter induces a myeloproliferative disease
}

\author{
Iris T. Chan, ${ }^{1}$ Jeffery L. Kutok, ${ }^{2}$ Ifor R. Williams, ${ }^{3}$ Sarah Cohen, ${ }^{1}$ Lauren Kelly, ${ }^{1}$ \\ Hirokazu Shigematsu, ${ }^{4}$ Leisa Johnson, ${ }^{5}$ Koichi Akashi, ${ }^{4}$ David A. Tuveson, ${ }^{6}$ \\ Tyler Jacks, ${ }^{7,8}$ and D. Gary Gilliland ${ }^{1,4,9}$
}

\author{
${ }^{1}$ Division of Hematology, Department of Medicine, and \\ ${ }^{2}$ Department of Pathology, Brigham and Women's Hospital, Harvard Medical School, Boston, Massachusetts, USA \\ ${ }^{3}$ Department of Pathology, Emory University School of Medicine, Atlanta, Georgia, USA \\ ${ }^{4}$ Department of Cancer Immunology and AIDS, Dana-Farber Cancer Institute, Boston, Massachusetts, USA \\ ${ }^{5}$ Exelixis Inc., South San Francisco, California, USA \\ ${ }^{6}$ Departments of Medicine and Cancer Biology, Abramson Family Cancer Research Institute, Abramson Cancer Center of the \\ University of Pennsylvania School of Medicine, Philadelphia, Pennsylvania, USA \\ ${ }^{7}$ Department of Biology and Center for Cancer Research, Massachusetts Institute of Technology, Cambridge, \\ Massachusetts, USA \\ ${ }^{8}$ Howard Hughes Medical Institute, Center for Cancer Research, Cambridge, Massachusetts, USA \\ ${ }^{9}$ Howard Hughes Medical Institute, Harvard Medical School, Boston, Massachusetts, USA
}

\begin{abstract}
Oncogenic ras alleles are among the most common mutations found in patients with acute myeloid leukemia (AML). Previously, the role of oncogenic ras in cancer was assessed in model systems overexpressing oncogenic ras from heterologous promoters. However, there is increasing evidence that subtle differences in gene dosage and regulation of gene expression from endogenous promoters play critical roles in cancer pathogenesis. We characterized the role of oncogenic $K$-ras expressed from its endogenous promoter in the hematopoietic system using a conditional allele and IFN-inducible, Cre-mediated recombination. Mice developed a completely penetrant myeloproliferative syndrome characterized by leukocytosis with normal maturation of myeloid lineage cells; myeloid hyperplasia in bone marrow; and extramedullary hematopoiesis in the spleen and liver. Flow cytometry confirmed the myeloproliferative phenotype. Genotypic and Western blot analysis demonstrated Cre-mediated excision and expression, respectively, of the oncogenic $K$-ras allele. Bone marrow cells formed growth factor-independent colonies in methylcellulose cultures, but the myeloproliferative disease was not transplantable into secondary recipients. Thus, oncogenic K-ras induces a myeloproliferative disorder but not AML, indicating that additional mutations are required for AML development. This model system will be useful for assessing the contribution of cooperating mutations in AML and testing ras inhibitors in vivo.
\end{abstract} J. Clin. Invest. 113:528-538 (2004). doi:10.1172/JCI200420476.

Received for publication November 5, 2003, and accepted in revised form January 7, 2004.

Address correspondence to: D. Gary Gilliland, Harvard Institutes of Medicine, 4 Blackfan Circle, Room 421, Boston, Massachusetts 02115, USA. Phone: (617) 525-5525; Fax: (617) 525-5530; E-mail: gillilan@hihg.med.harvard.edu. Conflict of interest: The authors have declared that no conflict of interest exists.

Nonstandard abbreviations used: acute myeloid leukemia (AML); GTPase-activating protein (GAP); guanine nucleotide exchange factor (GEF); phosphoinositide-3-kinase (PI3K); internal tandem duplication (ITD); neurofibromatosis 1 (NF1); juvenile myelomonocytic leukemia (JMML); long terminal repeat (LTR); mouse mammary tumor virus (MMTV); lox-stop-lox (LSL); polyinosinic-polycytidylic acid (pI-pC); allophycocyanin (APC); common myeloid progenitor (CMP); granulocytemonocyte progenitor (GMP); megakaryocyte-erythrocyte progenitor (MEP); stem cell factor (SCF); erythropoietin (EPO); pI-pC-treated LSL-K-ras G12D $/ \mathrm{Mx}^{+}-\mathrm{Cre}^{+}(\mathrm{KM}+)$; LSL-K-ras $\mathrm{G}^{2} \mathrm{D}^{+} / \mathrm{Mx} 1-\mathrm{Cre}^{+}$not treated with $\mathrm{pI}-\mathrm{pC}(\mathrm{KM}-)$; LSL-K-ras $\mathrm{G} 12 \mathrm{D}^{+}$treated with $\mathrm{pI}-\mathrm{pC}(\mathrm{K}+)$; $\mathrm{Mx1}$-Cre ${ }^{+}$treated with $\mathrm{pI}-\mathrm{pC}$ $(\mathrm{M}+)$; wild-type littermate treated with $\mathrm{pI}-\mathrm{pC}(\mathrm{WT}+)$; white blood cell (WBC); erythroid burst-forming unit (E-BFU); monocyte colony-forming unit (M-CFU); granulocyte-erythrocytemonocyte-megakaryocyte colony-forming unit (GEMM-CFU).

\section{Introduction}

Acute myeloid leukemia (AML) is characterized by an accumulation of immature myeloid precursors in the bone marrow and, in many cases, the peripheral blood. From analysis of recurrent chromosomal translocations in bone marrow samples from AML patients, it is clear that loss-of-function mutations in transcription factors critical for hematopoiesis are involved in leukemogenesis. These balanced reciprocal translocations often result in the expression of fusion proteins that act as dominant negative inhibitors of the normal transcription factors in hematopoietic development, such as the AML1-ETO product of the $t(8 ; 21)$ translocation and the PML-RAR $\alpha$ product of the $t(15 ; 17)$ translocation. Loss-of-function point mutations in transcription factors involved in hematopoietic differentiation, such as C/EBP $\alpha$ and AML1, have also been identified in AML. Although these mutations involving hematopoietic transcription factors are necessary for AML pathogenesis, they are not sufficient (1-4). It is hypothesized that the AML phenotype 
requires a combination of mutations in the hematopoietic progenitor cells, which contribute to impaired differentiation and an increased proliferation and/or survival advantage $(5,6)$. The ras proto-oncogenes are likely candidates for proteins in which gain-of-function mutations would confer the signals for enhanced cell proliferation and survival in AML pathogenesis.

The ras proteins are a family of guanine nucleotidebinding proteins involved in cell proliferation, differentiation, and survival (7-10). The ras signaling pathways are activated by a spectrum of hematopoietic cytokine receptors in response to ligand and therefore play important roles in the proliferation and enhanced survival of hematopoietic progenitors. Members of the ras family include K-ras, $\mathrm{N}$-ras, and $\mathrm{H}$-ras. They are expressed ubiquitously during development and must be post-translationally modified by farnesylation and/or geranylgeranylation for membrane localization and functional activity. The ras proteins cycle between an inactive GDP-bound state and an active GTP-bound state; this cycling is mediated by GTPase-activating proteins (GAPs) and guanine nucleotide exchange factors (GEFs). In the GTP-bound state, ras activates the Raf/MAP kinase pathway, with subsequent activation of transcription factors and altered expression of genes promoting cell proliferation and differentiation. The ras proteins can also promote cell survival by activating the phosphoinositide-3-kinase (PI3K) pathway, with subsequent stimulation of AKT kinase and inactivation of the proapoptotic protein Bad. The ras proteins also activate a multitude of downstream effectors (including Ral-GEFs, AF-6, PKC- $\zeta$, Nore1, Rin 1, RASSF1, and phospholipase $C \varepsilon$ ), whose roles in oncogenesis are incompletely understood. Functionally, the $\mathrm{H}-, \mathrm{N}$-, and $\mathrm{K}$-ras isoforms have different properties with respect to activation of downstream effectors, transformation abilities, post-translational modifications, subcellular localizations, role in mouse development, and relative frequency of mutation in various human tumors $(7,11)$.

Oncogenic ras mutations are present in approximately $25-44 \%$ of AML patients and are among the most frequently detected genetic alterations in $\operatorname{AML}(12,13)$. Activating $N$-ras mutations are detected in $20-25 \%$ of AML patients and $K$-ras mutations are seen in $10-15 \%$ of AML patients. These activating mutations most frequently involve single amino acid substitutions at ras codons 12,13 , or 61 , which abrogate intrinsic ras GTPase activity and lead to constitutive ras activation.

In the absence of oncogenic ras mutations, ras may be activated through other mechanisms, such as the oncogenic activation of upstream tyrosine kinases seen in a significant proportion of AML cells, with consequent accumulation of ras-GTP. Examples of tyrosine kinase gain-of-function mutations in AML include FLT3 activation loop point mutations, FLT3 juxtamembrane region internal tandem duplications (ITDs) (14), C-KIT point mutations (15), and the tyrosine kinase fusion products of chromosomal translocations such as TEL/ TRKC associated with $\mathrm{t}(12 ; 15)(16,17)$ or TEL/ABL associated with $\mathrm{t}(9 ; 12)(18,19)$. Most of these tyrosine kinase mutations confer growth factor-independent growth to hematopoietic cell lines and cause a myeloproliferative disease in mouse models $(17,20,21)$.

Dysregulation of ras-GAP is another mechanism of indirect ras activation in leukemic cells. Loss-of-function mutations in neurofibromatosis 1 (NF1), a rasGAP protein, lead to accumulation of high levels of rasGTP (22). Children with type 1 neurofibromatosis are predisposed to malignant myeloproliferative syndromes, which include monosomy 7 syndrome and juvenile myelomonocytic leukemia (JMML) (23). Mice heterozygous for NF1 deletion are prone to develop a myeloproliferative syndrome resembling human JMML (24). NF1-deficient mouse fetal liver cells demonstrate hypersensitivity to GM-CSF stimulation and elevated levels of ras-GTP $(25,26)$ and confer a JMML-like myeloproliferative disease upon transplantation (25).

To date, activating ras mutations have been studied in various cell culture, bone marrow transplantation, and transgenic mice model systems expressing ras from exogenous promoters. A variety of phenotypes has been reported. CD34 ${ }^{+}$stem cells transduced with amphotrophic retrovirus expressing oncogenic $N$-ras had impaired erythropoietin-induced erythroid differentiation at the late erythroblast stage, reminiscent of a myelodysplastic phenotype $(27,28)$, and impaired G-CSF- and GM-CSFinduced granulocytic differentiation at the blast/promyelocyte stage (29). In a transplant model using bone marrow cells retrovirally transduced with oncogenic $N$-ras, recipient mice developed myeloproliferative disorders with long latency (107-385 days) and incomplete penetrance, suggesting that secondary mutations were necessary for the phenotype (30). Mice transplanted with bone marrow cells retrovirally transduced with viral $H$-ras developed peripheral myeloid leukocytosis, as well as frequent pre-T thymic lymphomas and/or pre-B cell lymphoblastic leukemia/lymphomas (31). Mice transplanted with bone marrow cells expressing oncogenic $H$-ras from the Moloney MuLV long terminal repeat (LTR) promoter often developed thymic lymphomas (32). Transgenic mice expressing activated $\mathrm{N}$-ras from the mouse mammary tumor virus (MMTV) LTR developed lymphoblastic T cell and B cell lymphomas and poorly differentiated mammary carcinomas (33). Transgenic mice expressing viral $H$-ras from the MMTV promoter/enhancer developed B cell lymphoblastic lymphomas at low frequency (34).

As is evident from the studies described above, a consistent phenotype from oncogenic ras expression in hematopoietic cells has not been established, in part because different exogenous promoters were used to express various oncogenic ras isoforms at supraphysiological levels and often in nonphysiological tissues. The variety of malignancies that developed likely reflected the tissue specificities of the promoters used rather than the specific transforming capabilities of oncogenic ras. The phenotypes generated from overexpression of genes from exogenous reporters may be very different from the phenotypes that arise when genes are expressed from their endogenous reporters. The critical role of gene dosage in 
cancer is supported by data indicating that haploinsufficiency may contribute to oncogenesis $(35,36)$.

In this study, a conditional expression strategy was used to characterize the biological consequences of expressing oncogenic $K$-ras from its endogenous promoter in hematopoietic cells. Expression of oncogenic ras in the mice induced a myeloproliferative syndrome with short latency and high penetrance, similar to that observed with leukemia-associated activated receptor tyrosine kinases, and conferred growth factor-independent colony formation of primary bone marrow cells.

\section{Methods}

Mouse strains. Lox-stop-lox (LSL)-K-ras G12D mice (on mixed $129 \mathrm{~Sv} / \mathrm{Jae}$ and C57BL/6 backgrounds) were crossed to Mx1-Cre transgenic mice (37) (on a BALB/c background) to obtain double-transgenic LSL-K-ras

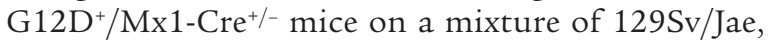
$\mathrm{C} 57 \mathrm{BL} / 6$, and $\mathrm{BALB} / \mathrm{c}$ genetic backgrounds. For induction of Cre expression, 4- to7-week-old mice were injected intraperitoneally with $250 \mu \mathrm{g}$ of polyinosinicpolycytidylic acid (pI-pC; Sigma-Aldrich, St. Louis, Missouri, USA) every other day for three doses. All mice were housed in microisolator cages, were monitored daily for evidence of disease, and were sacrificed when moribund. All experiments were conducted with the ethical approval of the Harvard Medical Area Standing Committee on Animals.

Molecular and biochemical analysis. LSL-K-ras G12D mice were genotyped by PCR amplification of genomic DNA obtained from tail tissue to detect the 500-bp wild-type K-ras and 550-bp floxed LSL-K-ras G12D products. For verification of Cre-mediated recombination, DNA from mouse bone marrow, spleen, and liver as well as from individual colonies of primary bone marrow methylcellulose cultures was amplified in PCR reactions using primers flanking the LSL cassette to detect the 285-bp wild-type $K$-ras and 315-bp excised lox-K-ras G12D products (38). For K-ras protein expression analysis, immunoprecipitation and Western blotting of tissue lysates from spleen, thymus, and lung were performed as described $(39,40)$.

Histopathology. Mouse organs were fixed for at least 72 hours in 10\% neutral buffered formalin (SigmaAldrich), dehydrated in alcohol, cleared in xylene, and infiltrated with paraffin. Tissue sections $4 \mu \mathrm{m}$ in thickness from paraffin-embedded tissues blocks were placed on charged slides, deparaffinized in xylene, rehydrated through graded alcohol solutions, and stained with hematoxylin and eosin.

Flow cytometric analysis. Spleen and bone marrow singlecell suspensions were prepared as described (41) by brief incubation in red blood cell lysis buffer (Gentra Systems, Minneapolis, Minnesota, USA) and freezing in 90\% fetal bovine serum and $10 \%$ dimethyl sulfoxide. Prior to analysis, cells were washed in PBS $/ 0.1 \% \mathrm{NaN}_{3} / 0.1 \%$ BSA and were preincubated for 20 minutes on ice with supernatant from the $2.4 \mathrm{G} 2$ hybridoma cell line (antiCD16/CD32; American Type Culture Collection, Rock- ville, Maryland, USA) to block nonspecific Fc receptor-mediated binding. Aliquots of $0.5 \times 10^{6}$ to $2.0 \times 10^{6}$ cells were stained for 20 minutes on ice with monoclonal antibodies, washed in staining buffer, and stained with secondary antibodies where necessary. Antibodies used were allophycocyanin (APC)-conjugated Gr-1 and CD4; phycoerythrin-conjugated Mac-1, Thy1.2, CD8, and CD117; biotin-conjugated CD19; and APC-conjugated streptavidin. All antibodies were purchased from Pharmingen (San Diego, California, USA), except for APC-CD4 and APC-streptavidin, which were purchased from Caltag (Burlingame, California, USA). Flow cytometric analysis was performed with a four-color FACSCalibur cytometer (Becton-Dickinson, Mountain View, California, USA). A minimum of 10,000 events was acquired and analyzed with CELLQUEST software.

For analysis of myeloid progenitors, bone marrow cells were stained as previously described (42) and analyzed with a highly modified triple-laser FACS (488-nm argon laser, 599-nm dye laser, and UV laser; FACSVantage; Becton Dickinson Immunocytometry Systems, Mountain View, California, USA). Myeloid progenitors were distinguished as $\mathrm{Lin}^{-} \mathrm{Sca}-{ }^{-}{ }^{-} \mathrm{c}-\mathrm{Kit}^{+} \mathrm{CD} 34^{+} \mathrm{Fc} \gamma \mathrm{RII} / \mathrm{III}^{\mathrm{lo}}$ common myeloid progenitors (CMPs), Lin ${ }^{-} \mathrm{Sca}-1^{-} \mathrm{C}^{-}$ $\mathrm{Kit}^{+} \mathrm{CD} 34^{+} \mathrm{Fc} \gamma \mathrm{RII} / \mathrm{III}{ }^{\text {hi }}$ granulocyte-monocyte progenitors (GMPs), and $\mathrm{Lin}^{-} \mathrm{Sca}-1^{-} \mathrm{c}-\mathrm{Kit}^{+} \mathrm{CD} 34-\mathrm{Fc} \gamma \mathrm{II} / \mathrm{III}^{\mathrm{lo}}$ megakaryocyte-erythrocyte progenitors (MEPs) (43).

Colony-forming assays. Primary bone marrow cells from pI-pC-treated mice were cultured in methylcellulosecontaining media using MethoCult GF M3434 media (StemCell Technologies, Vancouver, British Columbia, Canada) containing $50 \mathrm{ng} / \mathrm{ml}$ murine stem cell factor (SCF), $10 \mathrm{ng} / \mathrm{ml}$ murine IL-3, $10 \mathrm{ng} / \mathrm{ml}$ human IL-6, and 3 units/ml human erythropoietin (EPO), or MethoCult GF M3231 media from which SCF, IL3, IL6, and EPO were absent. For primary methylcellulose cultures, $4 \times 10^{3}$ to $1 \times 10^{5}$ cells were seeded in duplicate and harvested after 10 days. Cytospin preparations of individual colonies were stained with Wright-Giemsa solutions. Serial replating assays were performed as previously described (44) in two independent experiments with $10^{4}$ cells replated in duplicate for each round of replating and colony counts performed on day 7 .

Murine bone marrow transplantation. Bone marrow cells were harvested from the femurs and tibias of $\mathrm{pI}-\mathrm{pC}-$ treated LSL-K-ras G12D+/Mx1-Cre ${ }^{+}(\mathrm{KM}+)$ mice. After red blood cell lysis, cells were washed in PBS, resuspended in Hank's balanced salt solution (Invitrogen Life Technologies, Carlsbad, California, USA), and injected $\left(10^{6}\right.$ cells $\left./ 0.5 \mathrm{ml}\right)$ into the lateral tail veins of sublethally irradiated (650 cGy) wild-type littermates. Mice were housed in microisolator cages and were provided with autoclaved chow and acidified water.

\section{Results}

Generation of mice expressing endogenous levels of oncogenic $K$-ras in the hematopoietic system. We studied LSL-K-ras G12D mice harboring a conditional oncogenic K-ras allele 
targeted to the endogenous $K$-ras locus by homologous recombination. The conditional allele contains a cassette with a transcriptional termination stop codon flanked by loxP sites (LSL cassette) located upstream of a mutation of glycine to aspartic acid in codon 12 (38) (Figure 1a). The stop cassette prevents potential deleterious consequences of expression of the oncogenic $K$-ras allele during development. However, Cre recombinase-mediated excision of the stop cassette in adult animals allows expression of oncogenic $K$-ras from the endogenous $K$-ras promoter sequences, thus preserving temporal, lineageappropriate, and quantitative transcriptional regulation. For expression of oncogenic K-ras in the hematopoietic system, LSL-K-ras G12D mice were crossed to Mx1-Cre transgenic mice that express Cre from the IFN- $\alpha / \beta$-inducible Mx1 promoter (Figure 1b) (37). Cre expression from the $\mathrm{Mx} 1$ promoter is induced in vivo by treating mice with IFN- $\alpha / \beta$ or $\mathrm{pI}-\mathrm{pC}$, a synthetic double-stranded RNA that induces expression of endogenous IFN. In this way, Cre expression, subsequent excision of the stop cassette, and expression of oncogenic K-ras will occur in cells expressing the IFN receptor, including hematopoietic cells.

Oncogenic $K$-ras expression in hematopoietic cells results in a myeloproliferative disorder. All pI-pC-treated LSL-

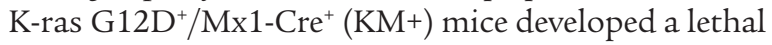
hematopoietic disease with a median survival of 35 days $(P<0.0001$ compared with negative controls by log rank test; range, 16-67 days) (Figure 1c). Of interest, all LSL-K-ras G12 $\mathrm{D}^{+} / \mathrm{Mx} 1-\mathrm{Cre}^{+}$mice that were not treated with pI-pC (KM- mice) also developed a similar hematopoietic disease with a longer median survival of 58 days $(P=0.0039, \mathrm{KM}+\mathrm{vs} . \mathrm{KM}-$ mice, by log rank test $)$. The negative controls, single-transgenic LSL-K-ras G12 $\mathrm{D}^{+}$mice, $\mathrm{Mx} 1-\mathrm{Cre}^{+}$mice, or wild-type littermate mice treated with pI-pC $\left(\mathrm{K}^{+}, \mathrm{M}+\right.$, or $\mathrm{WT}+$ mice, respectively), showed no evidence of disease. The predominant phenotype identified

\section{Figure 1}

Lethal myeloproliferative disease in mice expressing a conditional oncogenic $K$-ras allele. (a) Schematic of wild-type (top), floxed (middle), and activated (bottom) $K$-ras alleles. $K$-ras exons 0,1 , and 2 are depicted. Gene targeting to the endogenous $K$-ras locus generated the floxed LSL-K-ras G12D allele (38) containing a transcriptional termination codon flanked by loxP sites upstream of a mutation of glycine to aspartic acid in codon 12 in exon 1. Excision of the stop cassette by $\mathrm{Cre}$ recombinase allows expression of the oncogenic $K$-ras allele. Asterisk indicates G12D mutation in exon 1. (b) Breeding schematic of LSL-K-ras G12D and Mx1-Cre mice, with subsequent pl-pC treatment of progeny to generate $\mathrm{KM}+, \mathrm{KM}-, \mathrm{K}+, \mathrm{M}+$, and WT+ littermate mice. K, LSL-K-ras G12D; M, Mx1-Cre. + or indicates presence or absence of $\mathrm{pl}-\mathrm{pC}$ treatment. (c) Kaplan-Meier comparative survival analysis of $\mathrm{KM}+, \mathrm{KM}$ - and negative control mice. Cumulative survival was plotted against days after treatment with pl-pC. For KM- mice, cumulative survival was plotted against days after their littermates received pl-pC treatment. $\mathrm{KM}+(n=25)$ and $\mathrm{KM}-(n=8)$ mice developed a lethal myeloproliferative disease with median latencies of 35 and 58 days, respectively. $\mathrm{K}+(n=11)$, $\mathrm{M}+(n=8)$, and $\mathrm{WT}+(n=10)$ mice were healthy during an observation period of more than 200 days. (d) Splenomegaly in mice expressing oncogenic K-ras. Spleen weights (left to right): $\mathrm{K}+, 70 \mathrm{mg}$; $\mathrm{M}+, 130 \mathrm{mg} ; \mathrm{KM}+, 560 \mathrm{mg}$; and $\mathrm{KM}+, 2,200 \mathrm{mg}$. in all $\mathrm{KM}+$ mice examined was a myeloproliferative disorder characterized by leukocytosis, splenomegaly, and myeloid hyperplasia in the bone marrow. White blood cell (WBC) counts ranged between $18 \times 10^{3} / \mu \mathrm{l}$ and $99 \times 10^{3} / \mu \mathrm{l}$ with a median WBC count of $36 \times 10^{3} / \mu \mathrm{l}$ (Table 1). KM- mice also developed leukocytosis with median WBC counts of $35 \times 10^{3} / \mu$. In the vast majority of cases, leukocytosis in $\mathrm{KM}+$ mice was due to an increase in the granulocyte population. For example, in $\mathrm{KM}+$ mice, neutrophils accounted for $15-65 \%$ of WBCs (median, $42 \% ; n=22)$, compared with $\mathrm{K}^{+}, \mathrm{M}+$, and WT+ mice, in which neutrophils were $12-43 \%$ of WBCs (median, $19 \% ; n=24 ; P<0.001$ by Mann-Whitney test). There were no significant differences in the absolute numbers of other WBC subsets, although there was a slight increase in the percentage of atypical lymphocytes. $\mathrm{KM}+$ mice were anemic, with a mean hematocrit of $27 \%$ (range, 11-48\%), compared with a normal mean hematocrit of $45 \%$ in the $\mathrm{K}^{+}, \mathrm{M}+$, and $\mathrm{WT}+$ controls $(P<0.001$ by Mann-Whitney test). There were no appreciable differences in the platelet counts between experimental and control mice.

$\mathrm{KM}+$ mice were emaciated, with ruffled fur and moderate-to-severe palpable splenomegaly. Spleen weights ranged between 205 and $2,300 \mathrm{mg}$, compared with normal-sized spleens (67-133 mg) in $\mathrm{K}^{+}, \mathrm{M}^{+}$, and $\mathrm{WT}+$ negative control mice $(P<0.001$; Table 1 and Figure $1 \mathrm{~d})$. Hematoxylin and eosin-stained sections of spleen

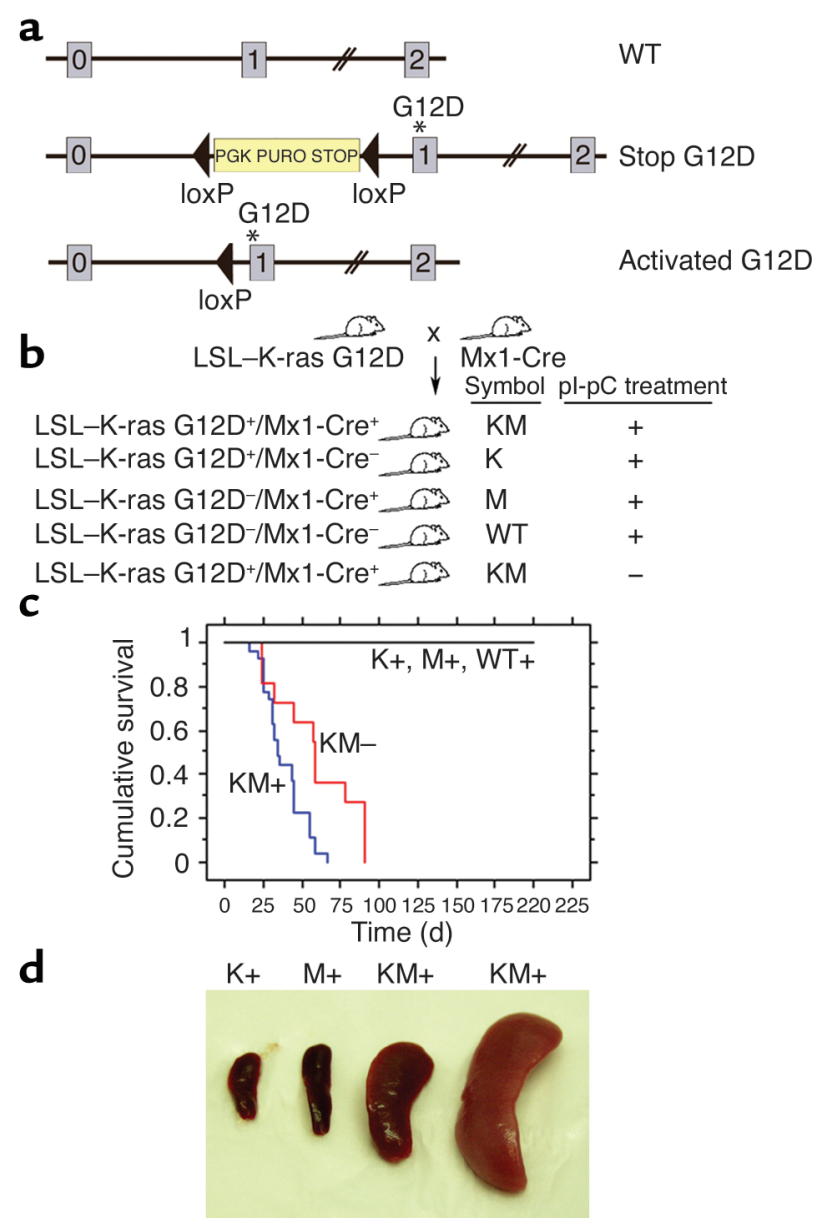


Table 1

Phenotype of KM+ mice and controls

\begin{tabular}{|c|c|c|c|c|c|c|c|}
\hline Genotype & pl-pC & $\begin{array}{c}\text { WBC } \times 10^{3} \text { per } \mu \mathrm{I} \\
\text { (median) }\end{array}$ & $\begin{array}{c}\mathrm{Hct} \% \\
\text { (median) }\end{array}$ & $\begin{array}{l}\text { Platelets per } \mu \mathrm{l} \\
\quad \text { (median) }\end{array}$ & $\begin{array}{l}\text { Spleen weight } \\
\text { (median) }\end{array}$ & $\begin{array}{l}\text { Liver weight } \\
\text { (median) }\end{array}$ & Phenotype \\
\hline KM & + & $\begin{array}{c}18-99(36) \\
n=22\end{array}$ & $\begin{array}{c}11-47(26) \\
n=22\end{array}$ & $\begin{array}{c}434-2,081(1,194) \\
n=22\end{array}$ & $\begin{array}{c}205-2,300(677) \\
n=25\end{array}$ & $\begin{array}{c}882-2,290(1,703) \\
n=25\end{array}$ & MPD \\
\hline KM & - & $\begin{array}{c}8-83(35) \\
n=6\end{array}$ & $\begin{array}{c}34-53(41) \\
n=6\end{array}$ & $\begin{array}{c}156-885(583) \\
n=6\end{array}$ & $\begin{array}{c}70-1,271(540) \\
n=8\end{array}$ & $\begin{array}{c}704-2,777(1491) \\
n=8\end{array}$ & MPD \\
\hline K & + & $\begin{array}{c}2.9-7.8(4.8) \\
n=9\end{array}$ & $\begin{array}{c}43-52(46) \\
n=9\end{array}$ & $\begin{array}{c}719-1,412(1,020) \\
n=9\end{array}$ & $\begin{array}{c}70-133(107) \\
n=11\end{array}$ & $\begin{array}{c}900-1,930(1,404) \\
n=11\end{array}$ & Normal \\
\hline M & + & $\begin{array}{c}2.6-5(4.6) \\
n=6\end{array}$ & $\begin{array}{c}36-47(43) \\
n=6\end{array}$ & $\begin{array}{c}518-1,218(904) \\
n=6\end{array}$ & $\begin{array}{c}80-124(104) \\
n=8\end{array}$ & $\begin{array}{c}940-2,000(1,292) \\
n=8\end{array}$ & Normal \\
\hline WT & + & $\begin{array}{c}4.3-8.4(6.3) \\
n=9\end{array}$ & $\begin{array}{c}43-50(47) \\
n=9\end{array}$ & $\begin{array}{c}551-1,336(1,074) \\
n=9\end{array}$ & $\begin{array}{c}67-120(90) \\
n=10\end{array}$ & $\begin{array}{c}1,069-1,756(1,437) \\
n=10\end{array}$ & Normal \\
\hline
\end{tabular}

Spleen and liver weights are presented in milligrams. MPD, myeloproliferative disease.

showed marked extramedullary hematopoiesis with effacement of splenic architecture and expansion of the red pulp compartment by varying degrees of granulocytic, monocytic, erythroid, and megakaryocytic lineage cells (Figure 2). Eleven of sixteen cases examined demonstrated a predominantly granulocytic/monocytic proliferation within the spleen and a hypercellular bone marrow revealing myeloid (predominantly granulocytic) hyperplasia (Figure 2). In the remaining five of sixteen cases examined, marked extramedullary hematopoiesis in the spleen was also observed; however, this represented a striking erythroid expansion with fewer numbers of granulocytic and monocytic forms. A more subtle expansion of myeloid elements was seen in the bone marrow of these mice. In all cases examined, the liver showed significant perivascular and periportal infiltration by populations of myeloid and erythroid cells identical to those seen in the spleen (Figure 2). The overall hematopoietic phenotype was similar to the myeloproliferative diseases induced in murine bone marrow transplant assays by tyrosine kinase fusions such as BCR-ABL, TEL-PDGFR $\beta$, TEL-TRKC, and TEL-JAK2 $(17,41$, $45,46)$. Interestingly, other pathological findings observed with high frequency but incomplete penetrance in $\mathrm{KM}+$ mice were squamous papillomas involving the anal and vulvo-vaginal skin (12 of 19), ear (8 of 22), esophageal mucosa (14 of 17), and oral mucosa (8 of 25) (Figure 3). In addition, multiple nodules were observed in the lungs of $\mathrm{KM}+$ mice $(10$ of 17), consisting of proliferating type II pneumocytes that stained positive for keratin (data not shown). These findings are consistent with the adenomas previously described in the lungs of LSL-Kras G12D mice treated with intranasal instillation of adenovirus-expressing Cre (38). Finally, thymic T cell lymphoblastic lymphomas (7 of 25) and nodal lymphoid hyperplasia distinct from sinusoidal infiltrates of myeloid elements ( 6 of 17) were also noted.

In $\mathrm{KM}$ - mice, extramedullary hematopoiesis in the spleen and liver was also evident. In six cases examined, one mouse demonstrated a marked myeloproliferative disease; four had mild, predom- inantly myeloid extramedullary hematopoiesis in the spleen and liver with mild myeloid (predominantly granulocytic) hyperplasia in the marrow; and one mouse had no hematopoietic abnormalities. In a subset of KMmice, pulmonary adenomas (five of six), thymic lymphomas (two of six), oral squamous papillomas (two of six), and ear squamous papillomas (two of six) were also observed. No vulvo-vaginal, anal or esophageal squamous papillomas were observed in $\mathrm{KM}$ - mice $(n=6)$.

Flow cytometric analysis of spleen cells (Figure 4a) from $\mathrm{KM}+$ mice further confirmed the myeloproliferative phenotype. In the spleen, $17-20 \%$ of cells were positive for the myeloid markers Gr-1 (Ly 6-G) and Mac-1, indicative of mature neutrophils, compared with 5-6\% for $\mathrm{K}+, \mathrm{M}+$, and WT+ negative control mice. In untreated $\mathrm{KM}-$ mice, Gr- $1^{+} / \mathrm{Mac}-1^{+}$cells represented $12 \%$ of spleen cells. The increased percentage of myeloid cells was associated with a concomitant decrease in the percentages of $\mathrm{CD} 4$ and

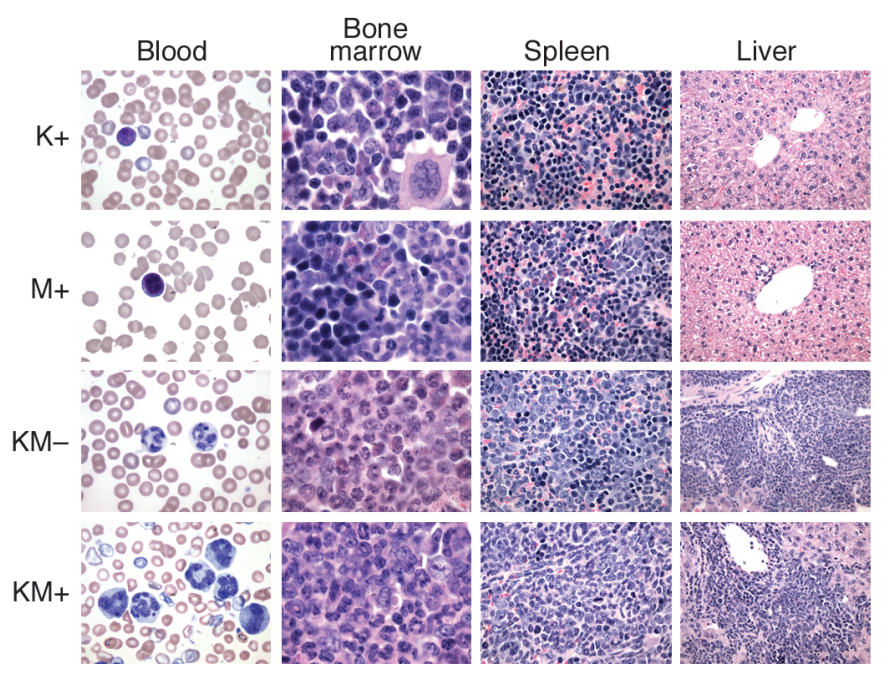

\section{Figure 2}

Mice expressing oncogenic K-ras develop a myeloproliferative disease. Representative histopathology (original magnifications in parentheses) from peripheral blood $(\times 100)$, bone marrow $(\times 100)$, spleen $(\times 40)$, and liver $(\times 20)$, showing expansion of predominantly mature myeloid elements, without an increase in immature/blast forms. 


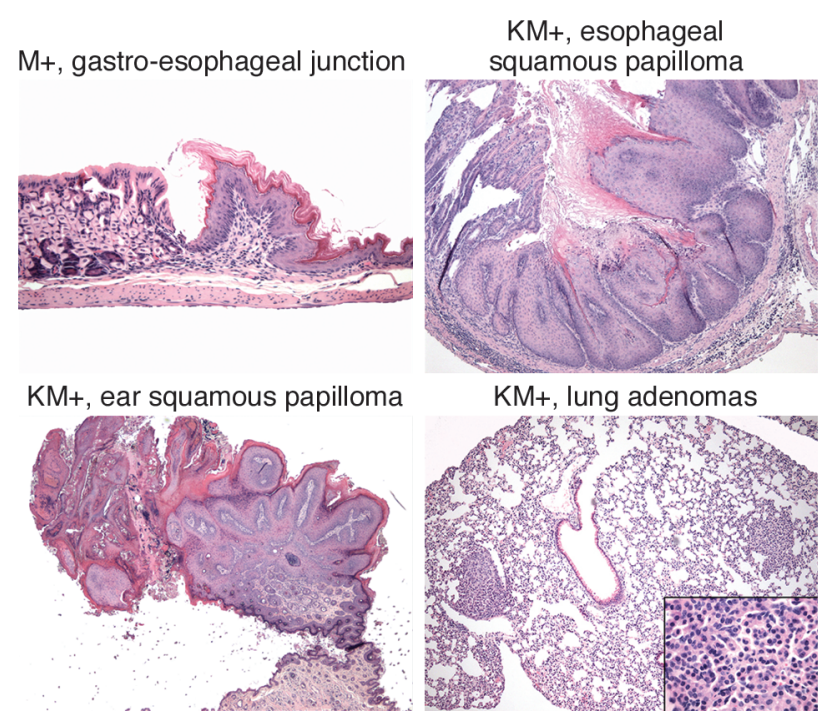

CD8 single-positive T cells and CD19+ $\mathrm{B}$ cells. Flow cytometric analysis of $\mathrm{KM}+$ bone marrow cells also showed evidence of myelomonocytic expansion, with $77-81 \%$ $\mathrm{Gr}-1^{+} / \mathrm{Mac}-1^{+}$cells, compared with $64-70 \% \mathrm{Gr}-1^{+} / \mathrm{Mac}-1^{+}$ cells in negative control $\mathrm{K}^{+}, \mathrm{M}+$, and $\mathrm{WT}+$ mice (Figure 4b). Erythroid lineage Ter- $119^{+}$cells were present in normal percentages, except in anemic $\mathrm{KM}+$ animals, which had an increased percentage of Ter- $119^{+}$cells (Figure 4a). Further analysis of $\mathrm{K}+, \mathrm{M}+$, and $\mathrm{KM}+$ bone marrow demonstrated no significant differences in the relative percentages of myeloid progenitor populations (Figure 5), composed of IL-7R $\alpha^{-}$Lin $^{-} \mathrm{C}-\mathrm{Kit}^{+} \mathrm{Sca}-1^{-}$cells (43), or in the relative percentages of CMP, GMP, and MEP subpopulations (Figure 5). This result must be interpreted with caution, as it is not known whether K-ras is normally expressed in the myeloid progenitor compartment. In $\mathrm{KM}+$ spleen, the relative percentages of CMP, GMP, and MEP populations increased, reflecting increased extramedullary hematopoiesis.

Oncogenic K-ras expression. Cre-mediated excision of the stop cassette upstream of the oncogenic K-ras allele was demonstrated via PCR of genomic DNA from various tissues (Figure 6a). Only DNA from diseased $\mathrm{KM}+$ and $\mathrm{KM}$ - tissues yielded a PCR product $30 \mathrm{bp}$ larger than the wild-type allele, corresponding to excision of the transcriptional stop cassette and the presence of the

\footnotetext{
Figure 4

Flow cytometric analysis of spleen and bone marrow cells. (a) Spleen cells from $\mathrm{KM}+(n=4), \mathrm{KM}-(n=2)$, and negative control $\mathrm{WT}+, \mathrm{K}+$, and $\mathrm{M}+$ mice $(n=2$ each) were stained with a combination of antibodies to Gr-1, Mac-1, CD14, CD45, Ter-119, Thy-1, and CD19. Dot plots were gated for live cells based on forward and side scatter profiles. Representative data are shown. (b) Bone marrow cells from $\mathrm{KM}+(n=4)$ and negative control mice $(n=2$ each $)$ were stained with a combination of antibodies to Gr-1, Mac-1, c-Kit, CD4, CD8, Ter-119, and CD45. Dot plots were gated for live cells based on forward and side scatter profiles. Representative data are shown. The percentages of cells in quadrants of interest are indicated.
}

\section{Figure 3}

Mice expressing oncogenic K-ras develop esophageal squamous papillomas and lung adenomas. Shown are normal gastroesophageal junction from $\mathrm{M}+$ mouse $(\times 10)$ and esophageal squamous papilloma $(\times 5)$, ear squamous papilloma $(\times 2)$, and lung adenomas $(\times 5$; inset, $\times 40)$ from $\mathrm{KM}+$ mice. Original magnifications in parentheses.

oncogenic $K$-ras allele containing a single loxP site. Expression of oncogenic K-ras protein was demonstrated by Western blot analysis in diseased $\mathrm{KM}+$ and $\mathrm{KM}$ - tissues but not in tissues from $\mathrm{K}^{+}, \mathrm{M}^{+}$, or WT+ negative control mice (Figure 6b).

Colony-forming unit activity. Bone marrow cells from $\mathrm{KM}+, \mathrm{K}^{+}$, and $\mathrm{M}+$ mice were plated in methylcellulose cultures in the presence or absence of growth factors (SCF, IL-3, IL-6, and EPO). All formed colonies in the presence of growth factors (Figure 7a). However, only bone marrow cells from $\mathrm{KM}+$ mice readily formed colonies in a growth factor-independent manner. These colonies were smaller in size and less differentiated than colonies that grew in the presence of growth factors. In addition, colonies derived from $\mathrm{KM}+$ bone marrow did not exhibit any enhanced serial replating

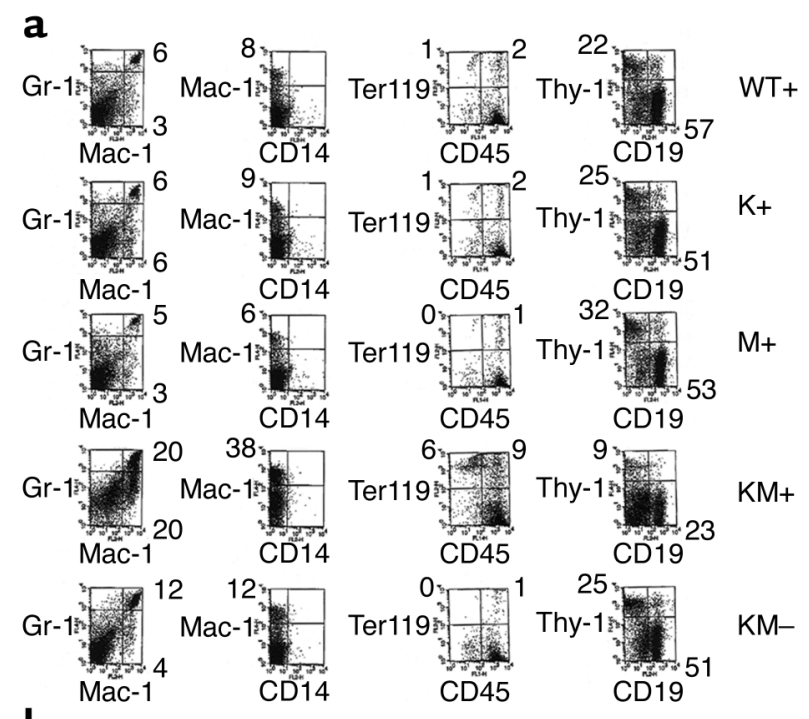

b

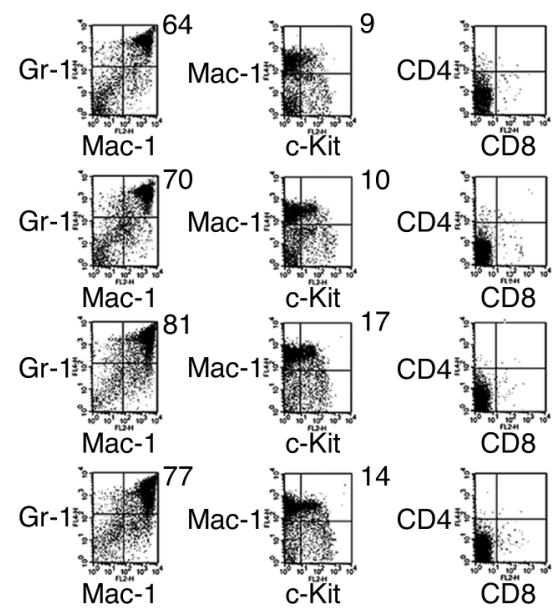

WT+

$\mathrm{K}+$

$\mathrm{KM}+$

$\mathrm{KM}+$ 


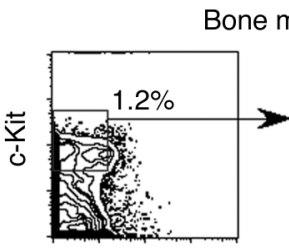

Sca-1

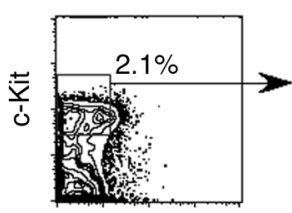

Sca-1

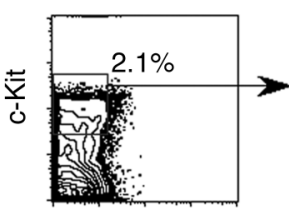

Sca-1

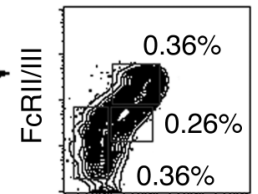

CD34

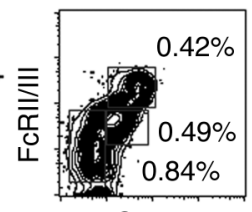

CD34

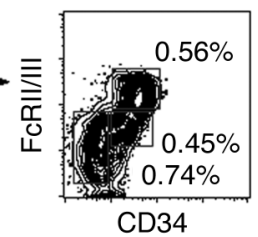

$\mathrm{K}+$

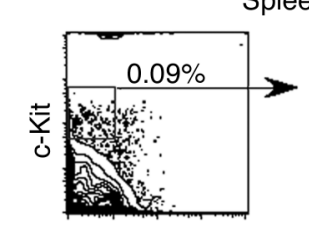

Sca-1

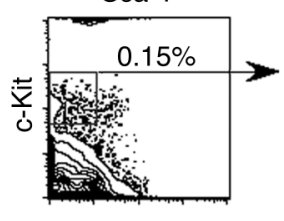

Sca-1

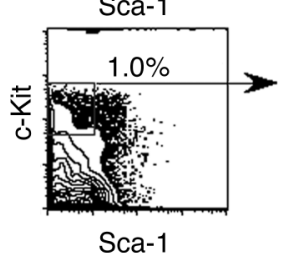

Sca-1
Spleen

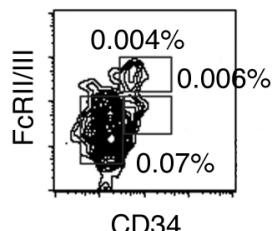

CD34

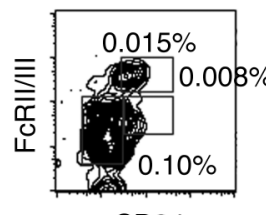

CD34

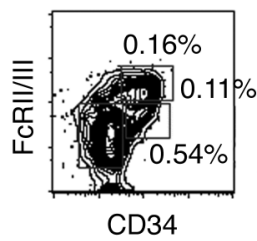

Figure 5

Analysis of myeloid progenitors in bone marrow and spleen of $\mathrm{K}+, \mathrm{M}+$, and $\mathrm{KM}+$ mice. Percentages of myeloid progenitors (IL-7R $\alpha^{-}$Lin-Sca $^{-}{ }^{-}{ }^{-}-\mathrm{Kit}^{+}$cells) and percentages of CMPs (Fc $\gamma \mathrm{R}^{\mathrm{lo}}$ CD34 $\left.{ }^{+}\right)$, GMPs $\left(\mathrm{Fc}_{\mathrm{R}} \mathrm{Ri}^{\mathrm{hi}} \mathrm{CD} 4^{+}\right)$, and MEPs (Fc $\left.\gamma \mathrm{R}^{\mathrm{lo}} \mathrm{CD} 34^{-}\right)$relative to whole bone marrow and spleen are indicated. Quadrants represent the respective gated populations of CMPs, GMPs, and MEPs. activity (Figure 7b). Genomic DNA prepared from individual methylcellulose culture colonies was assayed for the presence of the activated $K$-ras allele. Only DNA from individual $\mathrm{KM}+$ colonies yielded a PCR product corresponding to excision of the stop cassette and activation of the oncogenic $K$-ras allele (Figure 7c). The activated $K$-ras allele was detected in $\mathrm{KM}+$ colonies that grew in the presence or absence of growth factors. In individual methylcellulose colonies, the Cre excision efficiency was $100 \%$ in $\mathrm{KM}+$ bone marrow-derived cells $(n=42$; Figure 7 and data not shown). The phenotype of individual colonies was determined by microscopic visualization of Wright-Giemsa-stained cytospin preparations (Figure 7 , $\mathrm{d}$ and $\mathrm{e}$ ). In duplicate experiments, no erythroid burstforming unit (E-BFU) colonies were observed in $\mathrm{K}+, \mathrm{M}+$, or $\mathrm{KM}+$ methylcellulose cultures harvested on day 10. Subsequent experiments with $\mathrm{KM}+$ and negative control bone marrow cells demonstrated E-BFU colonies in comparable numbers when cultures were harvested on day 7 (data not shown). Colonies derived from $\mathrm{K}+, \mathrm{M}+$, or $\mathrm{KM}+$ bone marrow cells grown in the presence of growth factors formed granulocyte-monocyte colony-forming unit (GM-CFU) and granulocyte-erythrocyte-monocyte-megakaryocyte colony-forming unit (GEMM-CFU) colonies with similar efficiencies. In contrast, colonies derived from $\mathrm{KM}+$ bone marrow cells in the absence of growth factors were predominantly monocyte colony-forming units (M-CFUs), composed of >95\% macrophages. Similar results demonstrating growth factor-independent colony formation of predominantly M-CFUs were observed in methylcellulose cultures of oncogenic K-ras bone marrow cells in a model using LSL-K-ras G12D ${ }^{+} /$Lys-Cre $^{+}$mice in which the oncogenic $K$-ras allele was activated in cells expressing Cre driven by the lysozyme M promoter (I.T. Chan and D.G. Gilliland, unpublished observations).

Transplantability. Bone marrow cells $\left(10^{6}\right)$ from diseased $\mathrm{KM}+$ mice were transplanted into semilethally irradiated wild-type littermate secondary recipients. To date, all transplant recipients remain healthy and disease-free after 120 days (data not shown), indicating that the myeloproliferative disease was not transplantable into secondary recipients.

\section{Discussion}

Expression of oncogenic $K$-ras from its endogenous promoter in the hematopoietic system is sufficient to induce a myeloproliferative syndrome with relatively

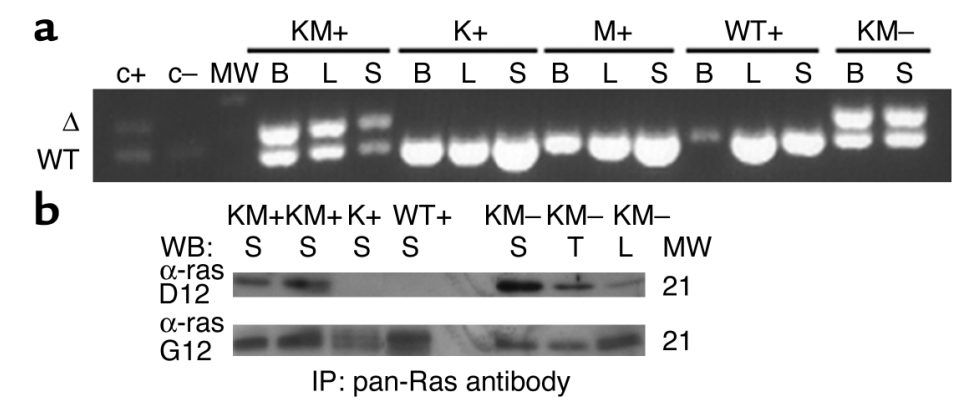

Figure 6

Cre-mediated activation of the oncogenic $K$-ras allele and expression of oncogenic $\mathrm{K}$-ras protein in diseased $\mathrm{KM}+$ and $\mathrm{KM}$ - tissues. (a) PCR for WT and activated $(\Delta) K$-ras alleles demonstrates the presence of the activated $K$-ras allele in $\mathrm{KM}+$ and $\mathrm{KM}$ - but not $\mathrm{K}+, \mathrm{M}+$, or $\mathrm{WT}+$ tissues. $\mathrm{B}$, bone marrow; L, liver; $\mathrm{S}$, spleen; $\mathrm{MW}$, molecular weight marker; $\mathrm{c}^{+}$, positive control DNA from an individual $\mathrm{KM}+$ methycellulose colony; c-, negative control DNA from an individual $\mathrm{K}+$ methylcellulose colony. (b) Oncogenic K-ras expression in diseased KM+ and KM- tissues. Tissues extracts were immunoprecipitated with a pan-ras antibody, followed by immunoblotting with polyclonal antibodies specific to wild-type ras ( $\alpha$-ras G12) and oncogenic ras G12D ( $\alpha$-ras D12). The WT ras doublet corresponds to farnesylated and unfarnesylated ras. S, spleen; T, thymic lymphoma; L, lung with multiple adenomas; WB, Western blot; IP, immunoprecipitation. 
a

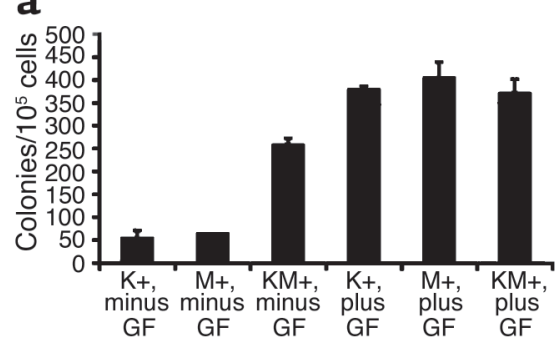

$c$

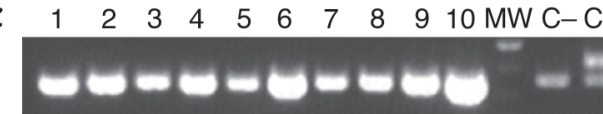

$\mathrm{K}+$, plus growth factors

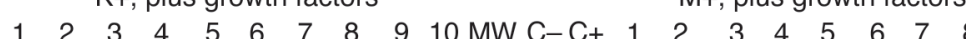

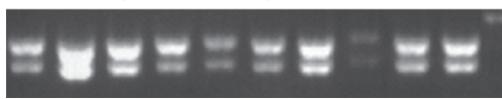

$\mathrm{KM}+$, plus growth factors

d $\mathrm{K}+$, plus growth factors $\mathrm{M}+$, plus growth factors

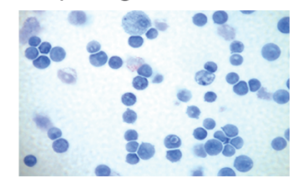

$\mathrm{KM}+$, plus growth factors

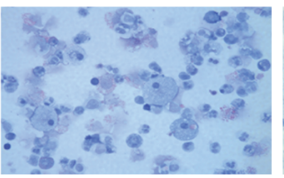

$\mathrm{M}+$, plus growth factors

$\mathrm{KM}+$, minus growth factors

e b

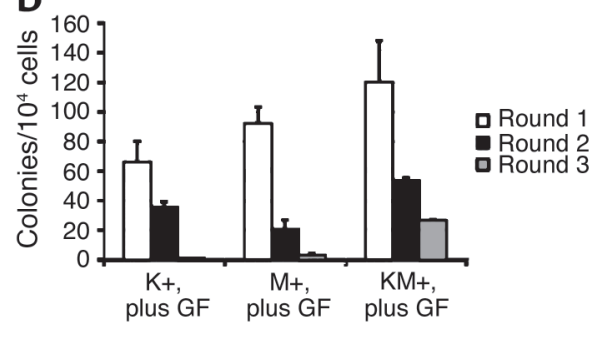

plus GF plus GF plus GF
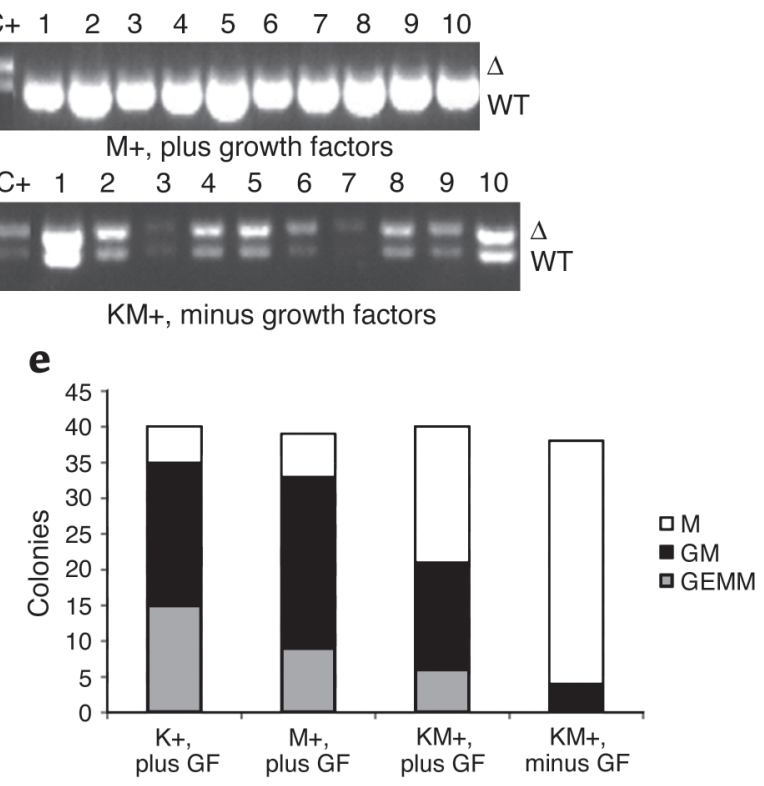

Figure 7

Methylcellulose cultures with $\mathrm{KM}+, \mathrm{K}+$, and $\mathrm{M}+$ bone marrow in the presence and absence of growth factors. (a) Number of colonies generated after methylcellulose culture of 100,000 bone marrow cells in the presence (plus) and absence (minus) of growth factors (GF: SCF, IL-3, and IL-6). Growth factor-independent colony-forming activity of KM+ bone marrow cells was demonstrated in two independent experiments. The values shown are the mean of duplicate cultures from one representative experiment. (b) Number of secondary, tertiary, and quaternary colonies generated in serial methylcellulose cultures using $10^{4}$ input bone marrow cells in the presence of growth factors. Serial replating assays were performed in two independent experiments. The values shown are the means of duplicate cultures from one representative experiment. (c) PCR for WT and activated $(\Delta) K$-ras alleles demonstrates presence of activated $K$-ras allele in individual methylcellulose colonies derived from $\mathrm{KM}+$ bone marrow in the presence and absence of growth factors, but not from $\mathrm{K}+$ or $\mathrm{M}+$ colonies. The intensity of the PCR products generated from KM+ growth factor-independent colonies was less robust than that from KM+ growth factor-dependent colonies, corresponding to lesser amounts of input template genomic DNA purified from the smaller individual growth factor-independent colonies. (d) Cytospins (Wright-Giemsa stain) of individual methylcellulose colonies show GM-CFUs derived from K+, M+, and KM+ bone marrow cultured in the presence of growth factors, and $\mathrm{M}-\mathrm{CFUs}$ from $\mathrm{KM}+$ bone marrow cultured in the absence of growth factors. (e) Quantitation of M-CFU (M), GM-CFU (GM), and GEMM-CFU (GEMM) colonies from K+, M+, and KM+ bone marrow cultured in the presence of growth factors and $\mathrm{KM}+$ bone marrow cultured in the absence of growth factors.

short latency. The myeloproliferative syndrome induced by oncogenic K-ras is similar to the myeloproliferative syndromes induced by activated receptor tyrosine kinases (e.g., FLT3-ITD, BCR-ABL, TEL-PDGFR $\beta$, and TEL-JAK2). This finding is somewhat surprising, as receptor tyrosine kinases activate multiple signaling pathways in addition to ras, such as the PI3K and JAK/STAT pathways. Indeed, disruption of PI3K/AKT or STAT signal transduction by pharmacologic or genetic strategies can abrogate transformation properties and diseases induced by receptor tyrosine kinases (46-52). As oncogenic K-ras is expressed from its endogenous promoter in this study, we may infer from these observations that oncogenic $K$-ras is at least as potent an allele as constitutively activated receptor tyrosine kinases that activate several signaling pathways including ras/MAP kinase. The inference is supported by epidemiological observations that activating mutations in FLT3 and ras are commonly found in AML, but rarely coexist in the same patient. The myeloproliferative disease observed in $\mathrm{KM}+$ mice appears similar to the JMML-like disease in mice transplanted with $\mathrm{NF}^{-/-}$fetal liver cells (25) and the myeloproliferative disease observed with long latency and incomplete penetrance in the oncogenic N-ras bone marrow transplant model (30).

It is interesting that the predominant phenotype induced by oncogenic K-ras is a granulocyte-rich myeloproliferative disease, as $\mathrm{Mx} 1$ promoter activation appears to occur very early in hematopoietic develop- 
ment. In a model of conditional AML1-ETO expression utilizing Mx1-Cre-mediated recombination, persistent expression of AML1-ETO occurs throughout the life of the mice, suggesting that Cre-mediated deletion of the stop cassette occurs in long-term repopulating hematopoietic progenitors (1). Mx1-Cre-induced expression of oncogenic K-ras in hematopoietic stem cells might be expected to engender not only myeloid proliferation but also megakaryocyte hyperplasia or lymphoproliferative disease. Still, neutrophil lineage cells may be more sensitive to activation of the ras/MAP kinase pathway. This hypothesis is supported by the observation that loss of NF1 function in the germline also favors development of neutrophil lineage disease. Oncogenic K-ras may contribute to lymphoid diseases, as there was evidence of lymphoid hyperplasia (enlarged lymph nodes) and lymphoid malignancy (lymphoblastic lymphoma) in the $\mathrm{KM}+$ and $\mathrm{KM}-$ mice. Mutations in ras have not been identified in patients with myeloproliferative diseases such as polycythemia vera and essential thrombocythemia (53-56). It is uncertain whether the erythroid hyperplasia seen in some $\mathrm{KM}+$ mice is the result of secondary erythroid hyperplasia in response to anemia or oncogenic $\mathrm{K}$-ras is capable of directly inducing erythropoiesis, albeit ineffectively. Excision of the stop cassette in erythroid, megakaryocytic, or T- and B-lymphoid-specific Cre strains will directly address the question of whether oncogenic K-ras is capable of inducing proliferative diseases in these lineages.

Earlier cell culture, transgenic and bone marrow transplant models of $\mathrm{H}$ - or $\mathrm{N}$-ras overexpression using heterologous promoters in the hematopoietic system yielded various phenotypes, including myeloproliferative diseases/leukemias with long latency and incomplete penetrance (30), impaired erythroid and myeloid differentiation suggestive of myelodysplasia (27-29), and pre-T thymic lymphomas and/or pre-B cell lymphoblastic leukemias/lymphomas (31-34). The variety of malignancies arising in these models likely reflects the tissue specificities and expression levels of the promoters used rather than the specific transforming properties of oncogenic ras. In $\mathrm{KM}+$ mice, one copy of the oncogenic $K$-ras allele is expressed from its endogenous promoter, which more accurately recapitulates the genotype of human AML.

$\mathrm{KM}$ - mice, which were not induced with $\mathrm{pI}-\mathrm{pC}$, also developed a myeloproliferative syndrome, albeit of intermediate severity, with lower WBC counts, mild to moderate splenomegaly, and longer latency than that of $\mathrm{KM}+$ mice. This is most likely due to endogenous IFN expression of sufficient levels to induce the Mx1-Cre transgene and activate oncogenic K-ras expression. Indeed, untreated AML1-ETO $/ \mathrm{Mx} 1-\mathrm{Cre}^{+}$mice demonstrate low levels of recombination in the bone marrow, ranging from $9 \%$ to $20 \%$ when monitored for 24 weeks (1). Similarly, untreated DNA polymerase $\beta^{+} / \mathrm{Mx} 1-\mathrm{Cre}^{+}$ mice demonstrate background recombination levels as high as $10 \%$ in the spleen, also attributed to endogenous
IFN production (37). It is likely that endogenous IFNs in untreated $\mathrm{KM}$ - mice activate expression of oncogenic $\mathrm{K}$-ras in a small percentage of long-term repopulating hematopoietic progenitors. Oncogenic K-ras expression confers a proliferative advantage to these progenitors; eventually, their expansion yields the myeloproliferative phenotype, although with slightly delayed latency.

$\mathrm{KM}+$ and $\mathrm{KM}-$ mice demonstrate additional histopathological findings with incomplete penetrance. Oncogenic ras mutations are detected in squamous papillomas and squamous cell carcinomas (57) and are important for initiation and progression of these lesions. Transgenic mice expressing $v$-H-ras from the $\zeta$-globin promoter develop skin papillomas with high frequency in response to trauma or chemical carcinogens (58). In rare instances, activating ras mutations have been reported in lymphomas (59). The pattern of premalignant tumors observed in $\mathrm{KM}+$ and $\mathrm{KM}$ - mice likely reflects the patterns of IFN-induced Mx1-Cre and subsequent oncogenic K-ras expression. In studies of Mx1-Cre-mediated recombination of a floxed DNA polymerase $\beta$ gene, pI-pC treatment yielded high recombination efficiencies in hematopoietic tissues (liver, 100\%; spleen, 94\%; and thymus, 40\%) and lower levels in nonhematopoietic tissues such as heart, kidney, lung, and duodenum (37). Experiments with mice doubly transgenic for the $\beta$-galactosidase reporter ROSA26tm1Sor and Mx1-Cre demonstrate Cre expression in liver, spleen, pulmonary endothelium, kidney, and gastric epithelium (60). Papillomas and thymic lymphomas have been previously observed in $30 \%$ of adenovirus-Cre-treated oncogenic K-ras mice (40). Additional mutations are likely required to form these premalignant lesions; the low frequency of these lesions observed in $\mathrm{KM}+$ and $\mathrm{KM}$ - mice may reflect a stochastic requirement for acquisition of additional oncogenic mutations, as well as the varying levels of IFN in those specific tissues. It is unlikely that development of these lesions depends on the penetrance of $\mathrm{pI}-\mathrm{pC}$ into the various tissues, as a subset of untreated $\mathrm{KM}$ - mice also develop the same pattern of papillomas, lung adenomas, and thymic lymphomas. $\mathrm{KM}+$ mice may be a useful model system for studying carcinogenesis in squamous cell cancers with particular utility in modeling cancer prevention strategies.

Previous studies of ras overexpression in primary cells demonstrated growth arrest and apoptosis (61-63). More recently, it has been hypothesized that thresholds of ras activity exist, such that low, intermittent signaling contributes to cellular homeostasis; modest increases promote proliferation without triggering protective tumor suppressor or growth arrest pathways; and high, sustained levels induce growth arrest and senescence (7). Consistent with this hypothesis, our results with primary bone marrow methylcellulose cultures show that oncogenic ras expression from its endogenous promoter promotes a proliferative signal that bypasses the requirement for signals from growth factors and allows colony formation independent of growth factors. 
Growth factor-independent colony-forming activity of bone marrow cells has also been described in TEL-JAK2 and $\mathrm{BCR} / \mathrm{ABL}$ murine bone marrow transplant models $(51,52)$. The oncogenic K-ras-expressing colonies do not have enhanced immortalization/self-renewal properties, as assessed in serial replating assays. In distinct contrast, primary mouse embryonic fibroblasts expressing endogenous levels of oncogenic K-ras bypass proliferative senescence and are immortalized (64). These differences are consistent with the hypothesis that the effects of oncogenic K-ras are dependent on cellular context (64). Additional mutations may be required to induce an immortalization or self-renewal phenotype in the hematopoietic cells.

Like activated receptor tyrosine kinases in myeloproliferative diseases, oncogenic ras is implicated in AML pathogenesis by virtue of its presence in a high percentage of AML samples. Still, oncogenic ras is not sufficient to induce AML, as oncogenic K-ras induced myeloproliferative disease is not transplantable into secondary recipients. Additional mutations are likely required. We favor a model in which the AML phenotype requires at least two cooperating mutations: one that promotes proliferation and enhanced survival (such as oncogenic ras or an activated receptor tyrosine kinase), and one associated with impaired differentiation and an immortalization phenotype (such as a loss-of-function mutation in a hematopoietic transcription factor, as has been reported for AML1-ETO; ref. 1). It will be important to test this hypothesis by analyzing oncogenic K-ras mice in the context of additional mutations associated with impaired hematopoietic differentiation, such as AML1ETO (1) or PML-RAR $\alpha$ (2). Ultimately, these oncogenic $\mathrm{K}$-ras/Mx1-Cre models will be useful for testing novel therapeutic agents, such as farnesyltransferase and geranylgeranyltransferase inhibitors, which target ras (65, 66), and other agents such as ERK inhibitors, which target the ras/MAP kinase pathway.

Oncogenic ras mutations have been detected in other hematologic malignancies such as multiple myeloma, myelodysplasia, chronic myelomonocytic leukemia, and acute lymphoblastic leukemia $(12,13)$. As noted above, crosses of LSL-K-ras G12D mice with other transgenic mice strains expressing Cre from hematopoietic-specific promoters, such as Lys-Cre, Vav-Cre, CD19-Cre, and Lck-Cre, may yield new insights to the contributions of oncogenic K-ras in myeloproliferative and lymphoproliferative diseases as well as AML.

Many downstream effectors are activated by ras, including the Raf/MEK/ERK pathway, the PI3K/AKT pathway, and RalGEFs. It would be interesting to determine which of these pathways is required for oncogenic ras-mediated myeloproliferative disease. Selective mutation of the ras effector domain (residues 32-40) can disrupt binding and activation of individual effector pathways (67-70). Generation of additional mice harboring various conditional oncogenic $K$-ras mutations activating only single effector pathways for subsequent crosses to Mx1-Cre mice will yield additional insights into the pathogenesis of ras- induced myeloproliferative diseases with implications for the development of molecularly targeted therapies.

Finally, data are gradually accumulating regarding differences between $\mathrm{H}-, \mathrm{N}$-, and $\mathrm{K}$-ras. The phenotypes of $H$-ras, $N$-ras, and $K$-ras knockout mice indicate clear distinctions in function and/or expression between family members. $H$-ras and $N$-ras knockout mice are viable with no overt abnormalities $(71,72)$. In contrast, $K$-ras knockout mice die at embryonic day 12.5 from severe anemia secondary to defects in the fetal liver microenvironment $(39,73)$. In addition, ras isoforms differ with respect to post-translational modifications, subcellular localization, and transformation properties $(7,11)$. Furthermore, $N$-ras mutations occur nearly exclusively in hematologic malignancies, whereas oncogenic $K$-ras and $H$-ras mutations are detected more often in solid tumors. In this Mx1-Cre mouse model, it is possible that the phenotypes from oncogenic $\mathrm{N}$ - or $\mathrm{H}$-ras expression may be different from that of oncogenic K-ras. It will be informative to study the analogous conditional oncogenic $\mathrm{H}$-ras and oncogenic $N$-ras alleles to understand differences in these ras isoforms and their contributions to oncogenesis.

\section{Acknowledgments}

We gratefully acknowledge administrative assistance from Alexis Bywater, and helpful discussions with members of the Gilliland lab. We also thank Benjamin Braun, Kevin Shannon, and Benjamin Neel for careful review of the manuscript. This work was supported in part by NIH grants DK51564 and CA66996 (D.G. Gilliland), a National Research Service Award for Postdoctoral Trainees (I.T. Chan) and the Leukemia and Lymphoma Society (D.G. Gilliland and I.T. Chan). D.G. Gilliland is an Associate Investigator of the Howard Hughes Medical Institute.

1. Higuchi, M., et al. 2002. Expression of a conditional AML1-ETO oncogene bypasses embryonic lethality and establishes a murine model of human $\mathrm{t}(8 ; 21)$ acute myeloid leukemia. Cancer Cell. 1:63-74.

2. Grisolano, J.L., Wesselschmidt, R.L., Pelicci, P.G., and Ley, T.J. 1997. Altered myeloid development and acute leukemia in transgenic mice expressing PML-RAR $\alpha$ under control of cathepsin G regulatory sequences. Blood. 89:376-387.

3. He, L.Z., et al. 1997. Acute leukemia with promyelocytic features in PML/RAR $\alpha$ transgenic mice. Proc. Natl. Acad. Sci. U. S. A. 94:5302-5307.

4. Brown, D., et al. 1997. A PMLRARalpha transgene initiates murine acute promyelocytic leukemia. Proc. Natl. Acad. Sci. U. S. A. 94:2551-2556.

5. Kelly, L.M., and Gilliland, D.G. 2002. Genetics of myeloid leukemias. Annu. Rev. Genomics Hum. Genet. 3:179-198.

6. Gilliland, D.G. 2001. Hematologic malignancies. Curr. Opin. Hematol. 8:189-191.

7. Hingorani, S.R., and Tuveson, D.A. 2003. Ras redux: rethinking how and where Ras acts. Curr. Opin. Genet. Dev. 13:6-13.

8. Bar-Sagi, D. 2001. A Ras by any other name. Mol. Cell. Biol. 21:1441-1443.

9. Scheele, J.S., Ripple, D., and Lubbert, M. 2000. The role of ras and other low molecular weight guanine nucleotide (GTP)-binding proteins during hematopoietic cell differentiation. Cell. Mol. Life Sci. 57:1950-1963.

10. Shields, J.M., Pruitt, K., McFall, A., Shaub, A., and Der, C.J. 2000. Understanding Ras: 'it ain't over 'til it's over'. Trends Cell Biol. 10:147-154.

11. Ellis, C.A., and Clark, G. 2000. The importance of being K-Ras. Cell. Signal. 12:425-434.

12. Beaupre, D.M., and Kurzrock, R. 1999. RAS and leukemia: from basic mechanisms to gene-directed therapy. J. Clin. Oncol. 17:1071-1079.

13. Reuter, C.W., Morgan, M.A., and Bergmann, L. 2000. Targeting the Ras signaling pathway: a rational, mechanism-based treatment for hematologic malignancies? Blood. 96:1655-1669.

14. Gilliland, D.G., and Griffin, J.D. 2002. The roles of FLT3 in hematopoiesis and leukemia. Blood. 100:1532-1542. 
15. Beghini, A., et al. 2000. C-kit mutations in core binding factor leukemias. Blood. 95:726-727.

16. Eguchi, M., et al. 1999. Fusion of ETV6 to neurotrophin-3 receptor TRKC in acute myeloid leukemia with $\mathrm{t}(12 ; 15)(\mathrm{p} 13 ; \mathrm{q} 25)$. Blood. 93:1355-1363.

17. Liu, Q., et al. 2000. Signal transduction and transforming properties of the TEL-TRKC fusions associated with $\mathrm{t}(12 ; 15)(\mathrm{p} 13 ; \mathrm{q} 25)$ in congenital fibrosarcoma and acute myelogenous leukemia. EMBOJ. 19:1827-1838.

18. Papadopoulos, P., Ridge, S.A., Boucher, C.A., Stocking, C., and Wiedemann, L.M. 1995. The novel activation of ABL by fusion to an ets-related gene, TEL. Cancer Res. 55:34-38.

19. Golub, T.R., Barker, G.F., Stegmaier, K., and Gilliland, D.G. 1996. Involvement of the TEL gene in hematologic malignancy by diverse molecular genetic mechanisms. Curr. Top. Microbiol. Immunol. 211:279-288.

20. Kelly, L.M., et al. 2002. FLT3 internal tandem duplication mutations associated with human acute myeloid leukemias induce myeloproliferative disease in a murine bone marrow transplant model. Blood. 99:310-318.

21. Million, R.P., Aster, J., Gilliland, D.G., and Van Etten, R.A. 2002. The Tel$\mathrm{Abl}$ (ETV6-Abl) tyrosine kinase, product of complex $(9 ; 12)$ translocations in human leukemia, induces distinct myeloproliferative disease in mice. Blood. 99:4568-4577.

22. Cichowski, K., and Jacks, T. 2001. NF1 tumor suppressor gene function: narrowing the GAP. Cell. 104:593-604.

23. Shannon, K.M., et al. 1994. Loss of the normal NF1 allele from the bone marrow of children with type 1 neurofibromatosis and malignant myeloid disorders. N. Engl. J. Med. 330:597-601.

24. Jacks, T., et al. 1994. Tumour predisposition in mice heterozygous for a targeted mutation in Nf1. Nat. Genet. 7:353-361.

25. Largaespada, D.A., Brannan, C.I., Jenkins, N.A., and Copeland, N.G. 1996 Nf1 deficiency causes Ras-mediated granulocyte/macrophage colony stimulating factor hypersensitivity and chronic myeloid leukaemia. Nat. Genet. 12:137-143.

26. Bollag, G., et al. 1996. Loss of NF1 results in activation of the Ras signaling pathway and leads to aberrant growth in haematopoietic cells. Nat. Genet. 12:144-148.

27. Darley, R.L., Hoy, T.G., Baines, P., Padua, R.A., and Burnett, A.K. 1997. Mutant N-RAS induces erythroid lineage dysplasia in human CD $34^{+}$cells. J. Exp. Med. 185:1337-1347.

28. Darley, R.L., et al. 2002. Protein kinase C mediates mutant N-Ras-induced developmental abnormalities in normal human erythroid cells. Blood. 100:4185-4192.

29. Darley, R.L., Hoy, T.G., Robinson, L., and Burnett, A.K. 1998. Mutant NRas blocks granulocytic differentiation of human $\mathrm{CD} 34^{+}$cells. $\mathrm{Br}$. J. Haematol. 102:289.

30. MacKenzie, K.L., Dolnikov, A., Millington, M., Shounan, Y., and Symonds, G. 1999. Mutant N-ras induces myeloproliferative disorders and apoptosis in bone marrow repopulated mice. Blood. 93:2043-2056.

31. Hawley, R.G., Fong, A.Z., Ngan, B.Y., and Hawley, T.S. 1995. Hematopoietic transforming potential of activated ras in chimeric mice. Oncogene. 11:1113-1123.

32. Dunbar, C.E., Crosier, P.S., and Nienhuis, A.W. 1991. Introduction of an activated RAS oncogene into murine bone marrow lymphoid progenitors via retroviral gene transfer results in thymic lymphomas. Oncogene Res. 6:39-51.

33. Mangues, R., Symmans, W.F., Lu, S., Schwartz, S., and Pellicer, A. 1996. Activated $\mathrm{N}$-ras oncogene and $\mathrm{N}$-ras proto-oncogene act through the same pathway for in vivo tumorigenesis. Oncogene. 13:1053-1063.

34. Sinn, E., et al. 1987. Coexpression of MMTV/v-Ha-ras and MMTV/c-myc genes in transgenic mice: synergistic action of oncogenes in vivo. Cell. 49:465-475.

35. Song, W.J., et al. 1999. Haploinsufficiency of CBFA2 causes familial thrombocytopenia with propensity to develop acute myelogenous leukaemia. Nat. Genet. 23:166-175.

36. Quon, K.C., and Berns, A. 2001. Haplo-insufficiency? Let me count the ways. Genes Dev. 15:2917-2921.

37. Kuhn, R., Schwenk, F., Aguet, M., and Rajewsky, K. 1995. Inducible gene targeting in mice. Science. 269:1427-1429.

38. Jackson, E.L., et al. 2001. Analysis of lung tumor initiation and progression using conditional expression of oncogenic K-ras. Genes Dev. 15:3243-3248.

39. Johnson, L., et al. 1997. K-ras is an essential gene in the mouse with partial functional overlap with N-ras. Genes Dev. 11:2468-2481.

40. Johnson, L., et al. 2001. Somatic activation of the K-ras oncogene causes early onset lung cancer in mice. Nature. 410:1111-1116.

41. Schwaller, J., et al. 1998. Transformation of hematopoietic cell lines to growth-factor independence and induction of a fatal myelo- and lymphoproliferative disease in mice by retrovirally transduced TEL/JAK2 fusion genes. EMBOJ. 17:5321-5333.

42. Miyamoto, T., et al. 2002. Myeloid or lymphoid promiscuity as a critical step in hematopoietic lineage commitment. Dev. Cell. 3:137-147.

43. Akashi, K., Traver, D., Miyamoto, T., and Weissman, I.L. 2000. A clonogenic common myeloid progenitor that gives rise to all myeloid lineages. Nature. 404:193-197.
44. Deguchi, K., et al. 2003. MOZ-TIF2-induced acute myeloid leukemia requires the $\mathrm{MOZ}$ nucleosome binding motif and TIF2-mediated recruitment of CBP. Cancer Cell. 3:259-271.

45. Daley, G.Q., Van Etten, R.A., and Baltimore, D. 1990. Induction of chronic myelogenous leukemia in mice by the $\mathrm{P} 210 \mathrm{bcr} / \mathrm{abl}$ gene of the Philadelphia chromosome. Science. 247:824-830.

46. Tomasson, M.H., et al. 2000. Fatal myeloproliferation, induced in mice by TEL/PDGFßR expression, depends on PDGFßR tyrosines 579/581. J. Clin. Invest. 105:423-432.

47. Nguyen, M.H., Ho, J.M., Beattie, B.K., and Barber, D.L. 2001. TEL-JAK2 mediates constitutive activation of the phosphatidylinositol 3 '-kinase/protein kinase B signaling pathway. J. Biol. Chem. 276:32704-32713.

48. Neshat, M.S., Raitano, A.B., Wang, H.G., Reed, J.C., and Sawyers, C.L. 2000 The survival function of the Bcr-Abl oncogene is mediated by Bad-dependent and -independent pathways: roles for phosphatidylinositol 3-kinase and Raf. Mol. Cell. Biol. 20:1179-1186.

49. Dierov, J., Xu, Q., Dierova, R., and Carroll, M. 2002. TEL/platelet-derived growth factor receptor beta activates phosphatidylinositol 3 (PI3) kinase and requires PI3 kinase to regulate the cell cycle. Blood. 99:1758-1765.

50. Sternberg, D.W., et al. 2001. The TEL/PDGFßR fusion in chronic myelomonocytic leukemia signals through STAT5-dependent and STAT5 independent pathways. Blood. 98:3390-3397.

51. Schwaller, J., et al. 2000. Stat5 is essential for the myelo- and lymphoproliferative disease induced by TEL/JAK2. Mol. Cell. 6:693-704.

52. Sattler, M., et al. 2002. Critical role for Gab2 in transformation by BCR/ABL. Cancer Cell. 1:479-492.

53. Tsurumi, S., et al. 2002. N-ras and p53 gene mutations in Japanese patients with myeloproliferative disorders. Am. J. Hematol. 71:131-133.

54. Mavrogianni, D., et al. 2002. Leukemogenic risk of hydroxyurea therapy as a single agent in polycythemia vera and essential thrombocythemia: $\mathrm{N}$ - and K-ras mutations and microsatellite instability in chromosomes 5 and 7 in 69 patients. Int. J. Hematol. 75:394-400.

55. Gaidano, G., Guerrasio, A., Serra, A., Rege-Cambrin, G., and Saglio, G. 1994. Molecular mechanisms of tumor progression in chronic myeloproliferative disorders. Leukemia. 8:S27-S29.

56. Gaidano, G., et al. 1997. Genetic lesions associated with blastic transformation of polycythemia vera and essential thrombocythemia. Genes Chromosomes Cancer. 19:250-255.

57. Yuspa, S.H. 1998. The pathogenesis of squamous cell cancer: lessons learned from studies of skin carcinogenesis. J. Dermatol. Sci. 17:1-7.

58. Leder, A., Kuo, A., Cardiff, R.D., Sinn, E., and Leder, P. 1990. v-Ha-ras transgene abrogates the initiation step in mouse skin tumorigenesis: effects of phorbol esters and retinoic acid. Proc. Natl. Acad. Sci. U. S. A. 87:9178-9182.

59. Nedergaard, T., Guldberg, P., Ralfkiaer, E., and Zeuthen, J. 1997. A one-step DGGE scanning method for detection of mutations in the $\mathrm{K}-, \mathrm{N}-$, and $\mathrm{H}$-ras oncogenes: mutations at codons 12,13 and 61 are rare in B-cell nonHodgkin's lymphoma. Int. J. Cancer. 71:364-369.

60. Schneider, A., Zhang, Y., Guan, Y., Davis, L.S., and Breyer, M.D. 2003 Differential, inducible gene targeting in renal epithelia, vascular endothelium, and viscera of Mx1Cre mice. Am. J. Physiol. Renal Physiol. 284:F411-F417.

61. Serrano, M., Lin, A.W., McCurrach, M.E., Beach, D., and Lowe, S.W. 1997 Oncogenic ras provokes premature cell senescence associated with accumulation of p53 and p16INK4a. Cell. 88:593-602.

62. Palmero, I., Pantoja, C., and Serrano, M. 1998. p19ARF links the tumour suppressor p53 to Ras. Nature. 395:125-126.

63. Ferbeyre, G., et al. 2002. Oncogenic ras and p53 cooperate to induce cellular senescence. Mol. Cell. Biol. 22:3497-3508.

64. Guerra, C., et al. 2003. Tumor induction by an endogenous K-ras oncogene is highly dependent on cellular context. Cancer Cell. 4:111-120.

65. Sebti, S.M., and Hamilton, A.D. 2000. Farnesyltransferase and geranylgeranyltransferase I inhibitors and cancer therapy: lessons from mechanism and bench-to-bedside translational studies. Oncogene. 19:6584-6593.

66. Ahmadian, M.R. 2002. Prospects for anti-ras drugs. Br. J. Haematol. 116:511-518

67. White, M.A., et al. 1995. Multiple Ras functions can contribute to mammalian cell transformation. Cell. 80:533-541.

68. Khosravi-Far, R., et al. 1996. Oncogenic Ras activation of Raf/mitogenactivated protein kinase-independent pathways is sufficient to cause tumorigenic transformation. Mol. Cell. Biol. 16:3923-3933.

69. Rodriguez-Viciana, P., et al. 1997. Role of phosphoinositide 3-OH kinase in cell transformation and control of the actin cytoskeleton by Ras. Cell. 89:457-467.

70. Hamad, N.M., et al. 2002. Distinct requirements for Ras oncogenesis in human versus mouse cells. Genes Dev. 16:2045-2057.

71. Umanoff, H., Edelmann, W., Pellicer, A., and Kucherlapati, R. 1995. The murine $\mathrm{N}$-ras gene is not essential for growth and development. Proc. Natl. Acad. Sci. U. S. A. 92:1709-1713

72. Ise, K., et al. 2000. Targeted deletion of the H-ras gene decreases tumor formation in mouse skin carcinogenesis. Oncogene. 19:2951-2956.

73. Koera, K., et al. 1997. K-ras is essential for the development of the mouse embryo. Oncogene. 15:1151-1159. 